\title{
Escribir soberano
}

\author{
Delmiro RochA \\ UNED \\ escrituraeimagen@filos.ucm.es
}

\section{Resumen}

Se aborda la deconstrucción de la soberanía desde el inclinado ángulo del loco soberano; desde una lectura de El Rey Lear de Shakespeare, obra en la que se divide dos veces la soberanía, al principio y al final de la pieza, y que abre la posibilidad de una lectura contemporánea de la misma en torno a dos ejes fundamentales: la locura y la muerte. Dos locuras y tres muertes soberanas.

Palabras claves: hostipitalidad, división, deconstrucción, locura, muerte, quizá.

\begin{abstract}
We approach the deconstruction of sovereignty from the slant point of view of the sovereign madman. We base this approach on the reading of King Lear by Shakespeare, a tragedy in which sovereignty is divided twice, at the beginning and the end of the play, and which opens the possibility of a contemporary reading of it around two fundamental axes: madness and death. Two sovereign madnesses and three sovereign deaths.
\end{abstract}

Key words: Hospitality, division, deconstruction, madness, death, perhaps.

El 4 de Marzo de 1963 en el Collège Philosophique Derrida lee lo siguiente:

Creo que la historicidad en general sería imposible sin una historia de la filosofía y creo que ésta sería imposible a su vez si no hubiese más que hipérbole, por una parte, o si no 
hubiese, por otra parte, más que estructuras históricas determinadas, Weltanschauungen finitas. La historicidad propia de la filosofía tiene su lugar y se constituye en ese pasaje, en ese diálogo entre la hipérbole y la estructura finita, entre el exceso sobre la totalidad y la totalidad cerrada, en la diferencia entre la historia y la historicidad; es decir, en el lugar, o más bien el momento en que el Cogito y todo lo que éste simboliza aquí (locura, desmesura, hipérbole, etc.) se dicen, se reafirman y decaen, se olvidan, de forma necesaria, hasta su reactivación, su despertar en otra ocasión de decir el exceso, que más tarde será también otra decadencia y otra crisis. [...] La crisis o el olvido no es quizás el lado accidental sino el destino de la filosofía hablante, que no puede vivir más que encerrando a la locura, pero que moriría como pensamiento, y bajo una violencia aún peor, si a cada instante una nueva palabra, aun encerrando en ella misma, en su presente, al loco del momento, no liberase a la antigua locura. Es sólo gracias a esta opresión de la locura como puede reinar un pensamiento-finito, es decir, una historia. Sin atenerse a un momento histórico determinado, sino extendiendo esta verdad a la historicidad en general, se podría decir que el reino de un pensamiento-finito sólo puede establecerse sobre la base del encierro y la humillación y el encadenamiento y la irrisión más o menos disimulada del loco que hay en nosotros, de un loco que sólo puede ser el loco de un logos, como padre, como señor, como rey. ${ }^{1}$

Extraigo de esta larga cita, a la vez que cerceno su encentadura, el final del final, la cola de su última frase, como si de una disección anatómica se tratase. Derrida dice: "del loco que hay en nosotros, de un loco que sólo puede ser el loco de un logos, como padre, como señor, como rey". ¿Qué significa, cómo debemos leer o, en todo caso, cómo podemos interpretar ese "nosotros"? Aparentemente es la primera persona del plural con la cual el pronombre personal universaliza la locura como algo intrínseco. Pero justo acompañando a un léxico como "padre", "señor" o "rey", ¿no es más bien ese "nosotros" un plural mayestático? Un plural que creó escuela entre escritores de toda índole y que hoy en día se confunde con el plural de modestia (pluralis modestiae) y el plural de autoría (pluralis auctoris). Pero el adjetivo mayestático deriva del término latín maiestas - atis, que significa "majestuoso", es decir, con la solemnidad o magnificencia propias de la majestad. Es el plural que la figura del soberano se arroga, incluyendo la figura del Papa, y que engloba bajo su persona la pluralidad de las cosas, cosas que pasan directamente a ser sus cosas. Es decir, la soberanía se constituye a través de un proceso de apropiación que, del todo, hace unidad. La pluralidad mayestática es, entonces, la indivisibilidad del Uno. Términos como "nosotros", "Nos" o "Vuestra" son otra forma de escribir "soberano". Pero, prolongando esta digresión inicial, ¿no hay, acaso, en todo escribir, una actitud intrínseca e irrechazable de control total, una predisposición, tanto más inconsciente, a dominar la escritura? ¿No es todo acto de escritura un escribir

\footnotetext{
1 Derrida, J.: La escritura y la diferencia, Barcelona, Anthropos, 1989, pp. 86-87. Traducción de Patricio Peñalver.
} 
soberano? Siguiendo a Derrida, como aquí confieso hacer, si la locura es aquello que el pensamiento encarcela para constituirse como tal, a la vez que debe liberarlo para no perecer "bajo una violencia aún peor", entonces, si alguien se adelanta y, acusándome de cierta falta de cordura, (me) dice: "éste está loco”, ¿no está acaso, con un gesto doble, coronándome?

Ciertamente, según el pensamiento de Derrida, colocar las palabras "escribir" y "soberano" la una detrás de la otra y situarlas a la cabeza de un texto, es decir, en el lugar que preside y, todavía sin contexto, gobierna cierto querer decir, parece, cuando menos, arriesgado. Parece haber cierta apariencia de exclusión. Lo soberano semeja limitarse hoy a lo que Derrida llamó, hace ya mucho tiempo, la clausura del libro. El escribir, siguiendo la analogía, sería la apertura del texto. La escritura derridiana, que según su poder diseminante no vuelve al padre (léase logos, señor, rey, etc), haría salir el "loco que hay en nosotros".

Según un gesto habitual en Derrida que consiste en leer con un libro en cada mano, siempre en los márgenes de la literatura y la filosofía, me gustaría abordar la deconstrucción de la soberanía desde el inclinado ángulo del loco soberano. Desde cierta escritura soberana que, tratando quizá de restituir una monarquía metafísica, abre en su escritura aquello mismo que pretende cerrar. Me detengo entonces en una lectura no lineal y necesariamente incompleta del que probablemente es el loco soberano más importante de la literatura occidental: El rey Lear de W. Shakespeare.

Derrida jamás ha publicado un texto sobre El rey Lear de Shakespeare. Conociendo el interés y la fuerza con que Derrida leía habitualmente a Shakespeare, yo comienzo pidiendo disculpas por esta lectura sucedánea, no especializada y pretendidamente deconstructiva que me dispongo a realizar. Lo dicho, pues.

En la primera escena del primer acto el rey Lear dice:

Sabed que hemos dividido el reino en tres partes. Es nuestro intento formal librar nuestra vejez del peso de los negocios y pasar ese fardo a hombros más jóvenes, en tanto que Nos, exentos de todo cuidado, nos encaminaremos hacia la muerte...2

Resulta asombrosa la cantidad de elementos que se ponen en juego desde el primer acto. Todo está sobre la mesa, incluso el destino fatal al que ciertamente se encamina el rey.

Primero, gráfica y formalmente, el rey habla en plural mayestático, con autoría pero sin modestia, y con el poder absoluto que constituye su palabra arconte. El decir performativo del rey hace ley, es la ley. Pero aquí el performativo se pliega sobre sí mismo al anunciar, desde su poder soberano, que ya no es más soberano, que renuncia a sí mismo. "Hemos [es decir, yo, el rey, la totalidad que en mi persona se agrupa] decidido dividir el reino en tres partes [es decir, hemos decidido dejar

\footnotetext{
2 Shakespeare, W.: El Rey Lear, RBA Ediciones, Barcelona, 2003, p. 81.
} 
de ser el rey]". Autoinmunidad soberana que limita — sujeta a una totalidad cerrada - al tiempo que excede la soberanía misma. El exceso aparecerá más antes que después, en la obra de Shakespeare, bajo la figura de la locura.

"En tanto que Nos [dice el rey todavía en plural y con mayúscula, letra capital pues él es todavía la cabeza], nos encaminaremos hacia la muerte". Hay aquí una referencia al desdoble de la personalidad, no un desdoble de personalidad psicológico sino jurídico, es decir, a las dos personas del rey que reconocía el derecho eclesiástico y que Derrida nos recuerda en el primer volumen del Seminario La bestia y el soberano cuando cita y analiza Los dos cuerpos del rey de Kantorowicz. El rey Lear cede la persona idealis, el rey inmortal, a sus herederos a la vez que encamina, en un mismo gesto, la persona personalis, el rey mortal, hacia la muerte. Sólo así el rey puede morir, según lo que al menos desde Bodin se entiende como soberanía, esto es, una e indivisible.

Ya aquí, desde el inicio de esta pieza de teatro majestuosa, el tema de la muerte sube a escena para quedarse ahí y no descender jamás. Lo mismo ocurre en los dos volúmenes del Seminario La bestia y el soberano, ese otro gran teatro magistral que compone uno de los bestiarios más ricos de nuestro tiempo. La muerte, pues, está en escena o, a lo sumo, acechando a paso de lobo, viendo sin ser vista, entre bastidores. Pues no otra cosa es la soberanía, nos recuerda Hobbes, que el derecho sobre la vida y la muerte.

Hay un detalle estilístico excepcional con el cual el rey Lear asume su muerte mucho antes de que se consuma. Consiste en renunciar al plural mayestático a partir del momento en que finaliza la cesión del poder soberano. Desde ese instante hasta la última escena del último acto, en la cual el rey Lear muere besando a Cordelia, su hija menor, el rey usará siempre la primera persona del singular. La muerte, pues, como posibilidad imposible para el rey. La división del rey en dos cuerpos como condición de imposibilidad para la soberanía. Pero, en El Rey Lear de Shakespeare, el rey no sólo tiene dos cuerpos sino que sufre, además, varias muertes. La primera de ellas, la acabamos de ver, es la renuncia al plural mayestático. Las siguientes serán, sucesivamente, la locura y la muerte de su persona personalis. Pero en la primera de sus muertes el rey Lear, desde el ejercicio de la soberanía que permite el exceso de renunciar a su palabra arconte, se resiste, no obstante, a perder una palabra: el nombre de rey.

Sólo queremos conservar el nombre de rey y las muestras exteriores de nuestra dignidad; en cuanto al poder, las rentas y el ejercicio de la monarquía, os lo abandonamos todo, queridos hijos. Y para confirmar la donación que os hago, compartid entre ambos esta corona... (Se quita la corona real y la da a sus yernos) ${ }^{3}$

3 Shakespeare, W.: El Rey Lear, RBA Ediciones, Barcelona, 2003, p. 86. 
He aquí otro pequeño texto cargado hasta el infinito de reenvíos significantes. El rey Lear quiere conservar el nombre de rey. Primera pregunta: ¿es la palabra "rey" un nombre? Sin duda es un nombre común sustantivo masculino, pero ¿es "rey" un nombre propio? Sin duda se puede escribir, y de hecho se escribe, con mayúscula para darle la altura y la alteza propias de la majestad. Sería, en este caso, el nombre más propio puesto que todo lo engloba en sí mismo. Pero el nombre "rey" funciona como suplemento en cuanto suplanta y subsume al nombre propio de la persona personalis; no obstante sólo lo puede hacer cuando la persona se duplica y pasa a portar además la persona idealis, es decir, no hay rey sin dos cuerpos. Sin embargo, en el caso del rey Lear, él quiere conservar el nombre de rey a pesar de haber renunciado al poder que erige y constituye dicho nombre. Otra vez, como vemos y seguiremos viendo, el exceso de la soberanía, el exceso como soberanía. Pero, para Derrida, tampoco el nombre propio resiste a la lógica de la différance, incluso diríamos que es el más afectado por ella puesto que su constitución misma se identifica con la lógica apropiante del logos. ¿De qué quiere seguir siendo propietario el rey Lear: del nombre o de lo que el nombre porta? ¿Se puede portar un nombre que no porta nada? ¿Quién porta, en realidad, a quién? En Derrida, no existe el nombre propio fuera de la cadena de reenvíos y remitencias diseminantes del lenguaje compuesto por huellas de huellas. Un nombre propio nunca se podría definir por sí mismo. Es decir, el nombre propio desgarra la propiedad del nombre en general, desapropia, desquicia, divide y no produce más conexión esencial entre concepto y mundo que la que produce el desvío del significante hacia otros significantes a través de la lógica del signo. En el caso del rey Lear, el nombre propio que pretende conservar es el que más desapropia y desbarata el concepto "propio", puesto que acaba de perder, en la cesión de su cargo, todas sus propiedades. El nombre propio porta la muerte y la inscribe allí donde pretende designar una vida exclusiva, es decir, propia. El rey Lear, en un intento desesperado y contradictorio, aspira a apropiarse del nombre de rey y de la dignidad de la realeza al mismo tiempo que se expropia a sí mismo del poder soberano. Este doble movimiento contradictorio de apropiación y expropiación que pretende apropiarse del sentido a la vez que lo deja en su alteridad es lo que Derrida denomina "exapropiación". Aquí tenemos, mediante un gesto inverso al que hasta aquí me trajo, a Derrida desde Shakespeare, Ecografias de la Televisión desde la boca del rey Lear:

Lo que llamo 'exapropiación' [es decir, ese intento contradictorio del rey Lear de intentar conservar su nombre] es ese doble movimiento en que me dirijo hacia el sentido con la intención de apropiarme de él [del nombre rey], pero a la vez sé y deseo, lo reconozca o no, que siga siendo extraño para mí, trascendente, otro, que permanezca allí donde hay alteridad [en sus yernos a quienes les cede su corona]. Si pudiera reapropiarme totalmente del sentido, exhaustivamente y sin dejar nada, no habría sentido. Si no quiero apropiarme de él en absoluto, tampoco lo hay. Así, pues, hace falta (el 'faltar' de ese 
'hace falta' es la existencia misma en general), un movimiento de apropiación terminado, una exapropiación"4.

Un exceso doble constituye la exapropiación. Un exceso sobre la propiedad de lo propio. El rey Lear incurre en este exceso bajo una hipérbole doble. En primer lugar, una hipérbole parricida o regicida, esto es, cuando el rey intenta acabar con su cuerpo soberano, persona idealis, volviendo la soberanía contra sí misma. En segundo lugar, cuando Lear intenta recuperar el poder bajo el nombre de "rey" yendo en contra de la ley que él mismo instauró con su palabra soberana. Una ley que viola la ley. Una soberanía que se divide a sí misma. Pues no hay que olvidar que en 1608, año en que se reconoce la primera edición de El rey Lear y año en que Francia amplia - a la vez que divide - su soberanía con la fundación del Quebec, y tan solo 28 años después de que el filósofo francés J. Bodin publique Los seis libros de la república (1576), en 1608, pues, la pieza de teatro El rey Lear de Shakespeare comienza por ordenar una división de la soberanía. "Sabed que hemos dividido el reino en tres partes", dice el rey Lear en la tercera página de la edición que yo manejo. Y apenas unas líneas más arriba, en la primera intervención del rey Lear en la obra de teatro, éste dice: "Id a buscar al rey de Francia y al duque de Borgoña". Ambos eran los pretendientes de Cordelia, la hija menor del rey, y pretendientes a su vez de la herencia soberana de Lear. La obra comienza, entonces, cuando el rey Lear manda llamar al rey de Francia para proceder al reparto de su soberanía o, lo que es lo mismo, al reparto de sus tres hijas. Parece como si Shakespeare mandase llamar a Bodin (muerto apenas siete años antes de la primera representación de la obra) para decirle que, frente a su idea de soberanía Una e indivisible defendida desde su puesto en el tribunal superior de justicia en el Parlamento de París, él, Shakespeare, va a comenzar por una división de la soberanía.

Una vez más el rey Lear comienza por ejercer el exceso, la soberanía como exceso, y pretende dividir lo indivisible y compartir lo incompartible a través de una donación sin precedentes. Más allá de la fantasía histórica o del mito celta que hace historia, no podemos obviar las palabras de Derrida cuando, sin querer ejercer de teórico político, postula lo siguiente:

Y si tuviese que proponer aquí una tesis política, ésta no sería la de la oposición de la soberanía y la no-soberanía como oposición del bien al mal o del bien que es un mal al mal que desea el bien sino otra política de la partición de la soberanía, a saber, de la partición de lo incompartible y de la división de lo indivisible. ${ }^{5}$

El rey Lear propone dos modalidades distintas de división y reparto. Primero,

\footnotetext{
4 Derrida: Ecografías de la Televisión. Entrevistas filmadas, Buenos Aires, Eudeba, 1998, p.137. Los corchetes no son de Derrida sino del autor de este artículo.

5 J. Derrida: "El Bien soberano o estar malo de ganas de soberanía", Revista Archipiélago 75, 2007, pp. 94-95.
} 
divide y cede su reino en dos partes para ser compartido por sus dos hijas mayores: Gonerila y Regana. Segundo, dona la monarquía pero quiere seguir conservando la majestad, es decir, el nombre de rey. Podemos ver aquí una deconstrucción de la soberanía que pasa por la división y la partición de lo incompartible. Y aunque de hecho esta división será el desencadenante de la trama y del drama que describe el teatro que nos ocupa, y en el cual por otro lado todavía estamos, esa misma división imposible seguirá constituyendo la condición de imposibilidad para la deconstrucción de la soberanía si entendemos, con Derrida, la deconstrucción como una experiencia de lo imposible que apuesta por la divisibilidad infinita.

El rey Lear, después de dividir su hacienda entre sus dos hijas mayores y después de renunciar a su tercera hija, Cordelia, su preferida, rompiendo incluso desde su palabra soberana todo lazo natural y sanguíneo para con ella, situando así la soberanía por encima de toda determinación natural y forzando su exilio a Francia, lugar donde todavía reinaba la monarquía indivisible, el rey comienza a adentrarse en lo que supone la segunda de sus muertes: la locura.

Esta catarata de asuntos y cuestiones políticas se ponen en juego en las pocas páginas de la primera escena del primer acto. Es todavía ahí donde el Conde de Kent acusa al rey de falta de cordura, para defender la monarquía e intentar evitar el exilio de Cordelia. Aquí comienza la segunda muerte del rey Lear.

El Rey Lear (a Kent)- El arco está tendido y la cuerda tirante. Guarda que la flecha te dé. Kent- Al contrario, que me dé, aunque la punta penetre hasta el corazón. Kent puede ser descortés porque Lear está demente. 6

El Conde de Kent, fiel vasallo y defensor acérrimo del rey a lo largo de toda la obra, es el primero en denunciar la enajenación del rey. Así, la aparente contradicción entre la acusación y la defensa que Kent formula paralelamente se disuelve si entendemos que el Conde no ha dejado jamás de ser un siervo leal puesto que a quien se opone no es al rey Lear sino a la locura que se ha apoderado de él y que lo suplanta al tiempo que lo destituye. El Conde de Kent sigue encadenado, cual representante de toda la filosofía occidental, a la articulación metafísica que une la Razón al sentido y al poder. El logos, para ir deprisa, sería lo que ha perdido el rey, su palabra soberana. Pero es solamente mediante el discurso supuestamente enajenado del rey como el Conde de Kent niega el logos a Lear, dicho de otra forma, lo acusa de mantener un discurso sin Discurso, un logos sin Logos. Y, para eso, es necesario que el discurso de Kent sí sea un discurso, un discurso con Discurso. Kent parece sostener un discurso "foucaultiano" al objetivar la locura, pues no puede aceptar una división de la soberanía tan demente como la que el rey Lear pretende.

6 Shakespeare 2003, op. cit. (nota 2), pp. 86-87. 
La expresión «decir la locura misma» es contradictoria en sí misma. Decir la locura sin expulsarla en la objetividad es dejarla que se diga ella misma. Pero la locura es, por esencia, lo que no se dice: es, dice profundamente Foucault, «la ausencia de obra».7

El rey muere por segunda vez y hace duelo de sí mismo, de su yo muerto, duelo consigo y por sí, duelo por su persona idealis que ha perecido en la locura. Lamenta la pérdida de su "yo rey", la muerte de sí mismo. Otra vez la soberanía como posibilidad para el exceso: Duelo imposible, duelo por sí. Todo trabajo, dice Derrida en Glas, es quizás un trabajo de duelo. A partir de este momento el rey es expulsado de palacio y deambula por un reino doblemente dividido, vaga por el solipsismo de su locura como un robinsón en su isla desierta y en compañía de su bufón. El bufón es la locura oficial, casi un ser humano, como Viernes, impropiamente humano. El bufón es la locura objetivada y aceptada, una locura que se dice a sí misma y que dice algo de sí, la locura que habita en palacio y que produce risas más que temores porque, bajo el sombrero colorido y con campañillas que la identifica, permanece en una prisión conceptual. El rey, en este destierro de sí, solamente se lleva de palacio a su bufón. Dos locuras caminando, dos cuerpos sin cabeza. Dos locuras distintas, teóricamente irreconciliables, que piensan la locura y se dan la mano. Como si Derrida y Foucault paseasen por los chiflados callejones de cierta soberanía.

Cabe resaltar que el rey Lear es acusado de locura fundamentalmente por dos actos excesivos o hiperbólicos, imposibles, pero que muestran la condición de soberano no como una comparación en la cual el rey siempre es más que lo otro (el más que...) sino como un superlativo absoluto (el más...). Es según el exceso como Derrida define lo propio de la soberanía:

Lo esencial y propio de la soberanía no es pues la grandura o la altura geométricamente medibles, sensibles o inteligibles, sino el exceso, la hipérbole, un exceso insaciable de desbordar cualquier límite determinable: más alto que la altura, más grande que la grandura, etc. Es lo más, lo más que lo que cuenta, lo absolutamente más, el suplemento absoluto que excede cualquier comparativo hacia un superlativo absoluto. ${ }^{8}$

Los dos excesos del rey Lear son: primero, la división y donación de la soberanía. Segundo, la renuncia de Cordelia negándole su condición de hija suya y situando el poder absoluto por encima incluso de la physis.

En semejante hipérbole, el rey convierte de un golpe a dos de sus tres hijas herederas en soberanas a la vez que en madres suyas. Al instante el rey es acusado de locura y cae inmediatamente en ella. La locura como muerte viva producirá una ten-

\footnotetext{
7 Derrida 1989, op. cit (nota 1), p. 63.

8 Derrida, J: Séminaire La bête et le souverain. Volume I (2001-2002), Paris, Galilée, 2008, p. 345346.
} 
dencia de la vida a la conservación de sí, un nuevo exceso que consiste en volver a la vida, esto es, en recuperar la cordura y el poder que se le asocia. Lear quiere volver a ser el Rey Lear. Será el bufón, figura de la única locura aceptada y circunscrita, quien realizará los mayores esfuerzos para expulsar a Lear de cierta locura que no le es propia, que le pertenece en propiedad al bufón. La locura y el exceso juegan un papel opuesto y superpuesto, pues son a la vez sinónimos y contrarios. El bufón será el más cuerdo entre los cuerdos, "el loco malicioso"; y el rey, el más loco entre los que quieren ser cuerdos, "el loco inocentón".

El Rey Lear- Eres un loco malicioso.

El Bufón- ¿Sabes tú, niño viejo, la diferencia que va de un loco malicioso a un loco inocentón?

El Rey Lear- No, hijo mío, enséñamelo.

El Bufón- Oye.

Ya que te han aconsejado

que abandones tu corona,

olvida, tío, tu trono

y abrázate a mi persona.

Dos locos verán los ojos

de tu cortesana grey:

uno en traje de bufón,

otro con traje de rey.

El Rey Lear- ¿Me llamas loco, hijo mío?

El bufón- Has abdicado todos los títulos que tenías por nacimiento

Kent- No es tan bobo como parece, milord.

El Bufón- No, a fe; y eso que hago un oficio del cual no quieren dejarme el privilegio los señores y magnates. Me disputan el monopolio de la locura, quieren ellos tener una parte. Hasta las damas me disputan esta profesión y cometen usurpaciones sobre mis tareas. Tío, dame un huevo y te daré dos coronas.

El rey Lear- ¿Cuáles son las dos coronas que me darás?

El Bufón- Tomaré el huevo, lo partiré por el medio, me comeré la yema y la clara y te daré las dos cáscaras. Cuando partiste en dos tu corona y diste la una y la otra parte, hiciste lo mismo que si en un camino lleno de barro te hubieses cargado el burro a cuestas. Había muy poco seso bajo la corona de tu calvicie el día que hiciste donación de tu corona de oro. Si lo que voy a decir ahora no es de un cuerdo más que de un loco, que den los azotes al primero que lo niegue. (Canta)

Para nosotros los locos

el año ha sido muy malo;

ya los cuerdos nos envidian

y pretenden imitarnos. ${ }^{9}$

\footnotetext{
${ }^{9}$ Shakespeare 2003, op. cit. (nota 2), pp. 112-114.
} 
El bufón no bromea sino que critica y denuncia. No se mofa, ni divierte, ni se burla sino que analiza, asevera y postula. Defiende una concepción racionalista de la soberanía clásica sosteniendo que una división de la soberanía ni siquiera un loco se atrevería a hacerla. Cierra las puertas a la novedad, al porvenir, y echa el cerrojo de la ortodoxia. La locura del rey Lear, incluso para el bufón chocarrero y cuentista, es excesiva. En efecto, el rey Lear excede y se excede. Pero el exceso, propio de la soberanía, que pone en marcha es un exceso que excede el exceso. Usa el exceso propiamente soberano para exceder la soberanía misma, para desde su "propiamente", desde su "en cuanto tal", desde su "en sí misma", salir fuera, al afuera de una totalidad, para expropiarse a sí y plegar la hipérbole. Mucho más allá de una economía soberana el rey Lear trabaja un pensamiento del don. Renuncia incondicionalmente a la soberanía para donarla, mediante una ofrenda sin reciprocidad, pues el que todo lo tiene nada puede esperar a cambio, y precisamente eso, "nada", es lo que puede esperar, espera sin espera. La mayor ofrenda posible, el don del rey Lear al otro, rompiendo ya la unidad, da a la alteridad la alteridad, a ese radicalmente otro que es habitualmente lo que está más cerca, justo al lado, en el abismo de un "muy" cerca, o incluso "demasiado" cerca. Es un pensamiento de la vida/la muerte el que atraviesa la cabeza sin cabeza, sin corona y sin cap, del rey Lear. Una autodecapitación parricida que no mata sino que da paso a la muerte abriendo un porvenir incalculable. La demasía o el colmo del exceso como soberanía que el rey Lear acomete consiste en hacer o en pretender hacer lo imposible. En dar aquello que es propiamente sí mismo, único e indivisible, y dividirlo en su darse al otro. Este es el poder auto-inmunitario que sobrepasa y viola la incondicionalidad del poder soberano al hacer lo imposible. Derrida pregunta respondiendo en el capítulo nueve del segundo volumen de La bestia y el soberano: “¿Qué es el poder si no puede más que el im-poder, si no puede más que lo que no puede, a saber, lo imposible?"10

Lear, en el intento desesperado de recuperar su poder, propone introducirse en la división y el reparto que él mismo ha llevado a cabo y compartir el poder con sus hijas. Regana, al rechazar esta opción, abre, sin embargo, la puerta a lo imposible: "¿Cómo queréis vos que en una misma casa obedezca tanta gente a distintos amos y viva en buena armonía? Es difícil, es casi imposible"11. Lo "casi imposible" pertenece ciertamente al dominio de lo posible. Regana niega esta posibilidad a Lear, bajo pretexto de imposible, a pesar de que ella misma la entiende como posible, como "casi imposible". Por otro lado, lo que ella niega por "casi imposible" es precisamente el poder dividido que ella ostenta con su hermana Gonerila. A lo largo de toda la obra este desplazamiento entre imposible y casi imposible es una constante que muestra la división sobre ambos terrenos, siempre (casi) imposible. Este "casi" imposible, este "por poco" o "cerca de" lo imposible, no es simplemente la aproxi-

10 Derrida, J. : Séminaire La bête et le souverain. Volume II (2002-2003), Paris, Galilée, 2010. p. 328. 11 Shakespeare 2003, op. cit. (nota 2), p. 159. 
mación de lo posible a lo imposible sino también la posibilidad imposible como la adyacencia o la vecindad de lo imposible con lo posible. El arrimo de la imposibilidad a lo posible es el arribo del porvenir o del quizá como acontecimiento inaudito, el anuncio del porvenir que quizá venga o la llegada del porvenir que viene quizá como quizá, bajo la forma de un peligroso quizá. Pero a Regana lo "casi imposible", el extremo de lo posible, le basta para confirmar la enajenación de Lear e insistir en que la locura debe estar fuera de palacio, lejos de la residencia del poder, del sentido y de la razón. Sin embargo, la locura es siempre el huésped de la razón, el pensionista o convidado de la cordura. No es un forastero que viene de fuera e invade la pureza del hogar propio sino que habita como anfitrión (segundo significado de huésped) injertando la alteridad y dividiendo toda vivienda.

Divivienda; divivir. División de la vivienda y vivir en división. Dos neologismos que me permito o me arriesgo a inscribir aquí para acercarme lentamente a la deconstrucción de lo propio de la soberanía que está en marcha, pues la locura en la corte del Rey Lear no se limita a las figuras del bufón y del rey. Hasta cinco personajes de palacio serán visitados por la demencia a lo largo de la obra.

En el tercer acto, Edgardo, que había abandonado el castillo real engañado so pena de traición, reaparece en escena con "aspecto de loco" en una choza donde el rey Lear, el bufón y el conde de Kent buscan cobijo de la tormenta que se avecina sobre sus cabezas 12 .

"(Aparece Edgardo con el aspecto de un loco.)"13 Así dice, entre paréntesis, la didascalia o acotación escénica inserta en el medio del texto. No explica necesariamente si Edgardo finge o no finge estar loco. Simplemente "aparece Edgardo con el aspecto de un loco". El aspecto de un loco no es un atributo constitutivo ni de un loco ni de un cuerdo. Edgardo aparece, fenomenalmente, "con el aspecto de un loco". La apostilla o acotación introduce al tercer demente de la historia. Ningún elemento es ajeno aquí a la realeza o a palacio. Toda la obra de teatro, incluidos sus márgenes escénicos, están acotados al mundo soberano, imperial y principesco. Incluidas las acotaciones escénicas, las apostillas, las didascalias o las cotas, término antiguo pero que resulta el más justo o ajustado en este caso.

[Paréntesis etimológico: La palabra "cota", que deriva del latín "quota", es, en una de sus acepciones, un sinónimo de "acotación”. Pero la etimología de la palabra "cota" tiene una doble vertiente o fuente significativa. Así, la palabra "cota", que deriva del francés antiguo, significa, en la segunda acepción del diccionario María Moliner, "Vestidura de los reyes de armas, sobre la que están bordados los escudos reales."]

12 A lo largo de toda la obra la palabra "cabeza" se repite constantemente. El texto habla de la cabeza, del cap, del cabeza de familia, pero también de la decapitación simbólica, el destronamiento del rey.

13 Shakespeare 2003, op. cit. (nota 2), p. 175. 
Double bind de la cota. Las escasas cotas, en la obra de Shakespeare como en todo el teatro clásico, son, en la obra de Derrida y según la deriva etimológica francesa, abundantísimas. Los símbolos, materiales e inmateriales, de la soberanía marcan la importancia de la visibilidad para el regio poder. No obstante, el verdadero poder del soberano radica en su (in)visibilidad. Su ser visible/invisible, su ser sin estar. Cualidad fantasmática del que es y no es. El "efecto visera" que Derrida desarrolla en Espectros de Marx a propósito del padre de Hamlet supone la autoridad constituida a través de un ver sin ser visto, del poder de verlo todo porque quien todo lo ve es, asimismo, invisible. Asimismo invisible, a-sí mismo invisible, mas no invisible a sí mismo. Invisibilidad para el otro como invisibilidad del otro. El otro teme y siente el poder de la ley porque no la ve, porque sin verla la ve, porque se hace visible en su invisibilidad. Sólo en cuanto invisible la ley es absolutamente visible, imposible de esquivar. División soberana de la cota: por un lado, anotación al margen que no se ve en la representación pero, sin embargo, se ve sin ser vista sobre la escena. Por otro lado, simbología visible del poder regio.

Así aparece en escena Edgardo, el hijo de Gloucester y aspirante un día al trono. "Aparece Edgardo con el aspecto de un loco". Escondido bajo harapos y refugiado en una choza. Vestimenta y alojamiento contrarios a los símbolos de la realeza. Anunciado por una cota, sostiene un discurso enajenado que oculta definitivamente su sangre azul, pero será precisamente este detalle el que llame la atención y la admiración de Lear. Dos cuerpos de la realeza que se atraen por la locura que los excluye de la realeza que los atrae.

Dos páginas después de que el bufón anuncie "esta noche glaciar nos volverá locos a todos"14, entra en la choza, antorcha en mano, el conde de Gloucester. Allí encuentra al rey Lear enajenado, a su hijo Edgardo con aspecto de loco, al bufón de la corte y al conde de Kent al que no reconoce. Gloucester confiesa "poco falta para que yo también me vuelva loco"15. Este grupo de locos serán, no obstante, los que defiendan y representen la cordura en la pieza. En cualquier caso, la locura parece apoderarse de toda la obra y de todos los personajes hasta el desenlace. Gloucester será acusado de loco por el rey Lear ${ }^{16}$, y el duque de Albany lo será a su vez por boca de Gonerila17. Al mismo tiempo, el rey Lear tilda a Edgardo, con aspecto de loco y discurso enajenado, de "filósofo", "sabio tebano", "noble filósofo", "mi filósofo" y "mi querido ateniense"18.

Tanto la locura como "el buen sentido" y la filosofía se encuentran del lado de los personajes caracterizados y/o acusados de demencia. Paralelamente, los actos

\footnotetext{
14 Shakespeare 2003, op. cit. (nota 2), p. 178.

15 Ibídem p. 183.

16 Ibidem p. 228

17 Ibídem p. 211.

18 Ibídem pp. 183-184.
} 
más ajenos al "buen sentido" o cordura clásica se sitúan en los personajes que juegan el papel de juiciosos y cabales. Esta inversión clásica de la trama revela sin embargo aspectos que hacen posible una lectura contemporánea de la obra. Más allá de la interpretación clásica de esta pieza de teatro majestuosa, que normalmente se asume como una escritura que defiende el amor filial, la philia y el respeto al padre (señor y soberano), aquí se ponen en juego temáticas contemporáneas como la división de la soberanía y la indivisibilidad entre razón y locura.

En El Rey Lear de Shakespeare la locura habita en palacio como huésped: a la vez invitado y anfitrión. La hospitalidad y la hostilidad, la acogida y el rechazo del otro, no son simplemente vecinos semánticos sino también coinquilinos. Si bien es cierto que la hospitalidad no es simplemente la ausencia de hostilidad, así como la hostilidad tampoco es simplemente la ausencia de hospitalidad, debería ser igual de cierto, al menos en principio, que allí donde hay, si la hay, hospitalidad habría también ausencia de hostilidad, y viceversa. Pero esta ausencia es siempre fenoménica o especulativa pues ambos términos se co-implican.

El término castellano "hoste" deriva del itálico "oste" y significa "posadero", y de ahí tenemos hostalero, hostalaje, hospicio, hostal o el inglés hostel; "hostal", sinónimo de hospedería o posada, establecimiento que ofrece alojamiento y comida al otro, deriva a su vez del latín "hospitalis", exactamente la misma raíz que tenemos para el término "hospital", establecimiento que se ocupa de dar cobijo sanitario al otro, y que antiguamente significaba "hospitalario". Asimismo, el término "hoste" (oste) nos conduce al francés hôtel y al castellano "hotel", que además de ser un hospedaje de mayor categoría y refinamiento que el hostal, era también en los inicios del siglo XV en Francia el nombre otorgado a las lujosas residencias con jardín de los señores y terratenientes, funcionando como sinónimo de "palacio", "chalet", "villa" o "quinta", y reenviando la etimología del lado del poder y de la autoridad. Por este lado, y forzando quizá demasiado la etimología, también encontramos en castellano el término "hospodar" que corresponde a una forma rumana o ucraniana y deriva del ruso "gospodar", que significa "señor": era el nombre que se daba a los antiguos príncipes soberanos de Moldavia y de Valaquia.

Pero el término "hoste", en castellano, tiene una segunda entrada que deriva directamente del latín "hostis" y significa "enemigo", "ejército" o "parte de un ejército", es decir "hueste", que también deriva del latín "hostis" y significa "tropa" o incluso "partidario". Si se continúa por esta segunda acepción encontraremos la palabra "hostaje", del provenzal "ostatge", que significa "rehén", así como "hostia", "hostilizar", "hostil" y "hostilidad".

El término "hoste", con su doble significación o significación bífida, se sitúa de lleno sobre el terreno gubernativo y abre en un mismo gesto dos vertientes políticas: la hospitalidad o la hostilidad como ética fronteriza que marca la relación del Estado con el otro. Así como para Carl Smith la hostilidad, es decir, el concepto de 
"enemigo" (hoste), marca el principio de la política, para Derrida la hospitalidad incondicional no será una opción ética frente a otras sino la ética misma a partir de la cual se toman o se abren las opciones:

La hospitalidad es la cultura misma y no es una ética entre otras. En la medida en que atañe tanto al ethos, a saber, a la morada, al chez-soi (a la casa, al hogar), al lugar de la estancia familiar como a la manera de estar ahí, a la manera de referirse a uno mismo y a los otros, a los otros como los suyos propios o como a unos extranjeros, la ética es hospitalidad, es de arriba a abajo coextensiva con la experiencia de la hospitalidad, cualquiera que sea la forma en que se la abra o se la limite. Pero por esa misma razón, y porque el ser-uno-mismo en casa (la ipseidad misma) supone una acogida o una inclusión del otro que uno intenta apropiarse, controlar, dominar, según diferentes modalidades de la violencia, hay una historia de la hospitalidad, una perversión siempre posible de $L a$ ley de la hospitalidad (que puede parecer incondicional) y de las leyes que vienen a limitarla, a condicionarla inscribiéndola en un derecho. ${ }^{19}$

Desde El Sofista y El Político de Platón hasta la introducción a Ser y Tiempo de Heidegger, la potestad o inclusión (control y violencia) del extranjero se asienta sobre la autoridad del paterfamilias. La soberanía del poder, potestas, presupone el hogar, la casa, el lugar de lo propio. El dominio o la familia del ipse, que se resume por economía con el sustantivo abstracto "ipseidad", sigue marcando la primera y la última frontera de lo político. A pesar de la profunda transformación que produce hoy en día el mundo de las telecomunicaciones y todo lo que su defensa o su agravio conlleva, el límite entre lo público y lo privado continúa presuponiendo el chez soi como lo propio, el hogar o la morada donde sólo manda uno, donde manda el Uno. La hospitalidad o la hostilidad, para la tradición que hoy heredamos, seguiría empezando a partir de ese presupuesto ontológico que otorga a la propiedad privada el poder y control absolutos sobre sí misma. Este presupuesto, además de afianzar una idea capitalística y extender sus raíces hasta el zócalo originario de la "fundación" europea, consolida el triunfo de una historia del sujeto, de la historia del sujeto soberano y dueño de sí.

No existe hospitalidad, en sentido clásico, sin soberanía del sí mismo sobre el propiohogar, pero como tampoco hay hospitalidad sin finitud, la soberanía sólo puede ejercerse filtrando, escogiendo, por lo tanto excluyendo y ejerciendo violencia. La injusticia, cierta injusticia, incluso cierto perjurio, comienza inmediatamente, desde el umbral del derecho a la hospitalidad. 20

19 Derrida, J.: Cosmopolitas de todos los países, ¡un esfuerzo más!, Valladolid, Cuatro Ediciones, 1996, pp. 41-42.

20 Derrida, J.: La Hospitalidad, Buenos Aires, Ediciones La Flor, $3^{\text {a }}$ ed. 2008, p. 59. 
Entonces, la violencia es intrínseca a la propia soberanía aunque ésta se decante, consciente y premeditadamente, por una ética de la hospitalidad. Esta contradicción conduce a la auto-inmunidad de la soberanía: para salvaguardar el lugar (de lo) propio, ya sea la casa familiar o el Estado, y para poder aplicar el derecho de la hospitalidad, es preciso no ser hospitalario, es preciso negar o cerrar, de entrada, la entrada al extranjero. Esta es la aporía: no hay lugar propio sin hostilidad de principio, no hay hospitalidad sin lugar propio. Aquello que da lugar y permite el derecho a la hospitalidad es la hostilidad que, a su vez, la niega.

Derrida enuncia esta aporía con el sintagma francés "pas d'hospitalité". Imposible traducción, pues en francés "pas" significa a la vez: la partícula negativa que permite traducir el sintagma como "no existe hospitalidad" o "nada de hospitalidad"; y el sustantivo "paso" que anuncia el movimiento de la hospitalidad o la marcha hacia la hospitalidad, "paso de hospitalidad".

Por un lado, no hay hospitalidad sin hostilidad pero, por el otro, la hospitalidad no se abre más allá del sujeto soberano de sí mismo sino que pertenece al propio chez soi, marca la instancia desgarrada de lo propio y divide infinitamente al sujeto; deconstrucción del sujeto. La hostipitalidad comienza en el otro, y el otro divide y habita, divive en la divivienda del chez soi.

Este proceso hostipitalario es el que (di)vive el rey Lear. El soberano absoluto, el dueño y señor, el paterfamilias de todas las familias sufre este proceso, por lo menos, doblemente doble:

Primera doblez: según un gesto de hospitalidad el rey da a sus yernos, [pues no hay que olvidar la lectura machista y misógina que atraviesa la obra: el rey necesita casar a sus hijas para poder dividir el poder], en una donación absoluta, la totalidad de su reino. En este gesto incluye al otro [sus hijas y especialmente sus yernos y las familias de estos] en su casa. Casa que deja de ser su casa (chez soi) en el propio dar. Esta hospitalidad desencadena la hostilidad que constituye la trama hasta su fatal desenlace. Al mismo tiempo, la hospitalidad del dar o del incluir al otro en su casa es una hospitalidad hostil, pues se hace a través de la palabra soberana que hace y es la ley. Es decir, la hospitalidad del rey Lear se otorga gracias a la violencia de su ley, no se invita al otro a entrar sino que se le ordena que entre. El rey Lear es dueño de sí mismo, de su casa, de su lugar propio y, por consiguiente, decide soberanamente quién y cuándo debe entrar. Esta hostilidad ontológica permite la hospitalidad, a su vez hostil, del soberano.

Segunda doblez: el cuerpo soberano del rey se divide en razón y locura. Huésped y anfitrión, huésped como anfitrión. La hostilidad habita en la casa de la razón, en la cabeza de la familia, y vulnera un supuesto límite externo desde dentro, desde el adentro que se proyecta hacia afuera. El expulsar, expeler, prohibir, desterrar, deportar, etc. al otro, a la alteridad de lo otro que está dentro como un agente impuro y que viene a contaminar la pacífica convivencia consigo del dueño 
que es uno, siempre ha constituido, aun con fines hospitalarios, la violencia de la frontera. Pero la hostipitalidad muestra que esta frontera se divide desde el interior proyectando hacia afuera una ilusión de límite unitario y sólido. Si hay frontera, si creamos frontera, es porque lo que se trata de impedir está ya de alguna forma a ambos lados del límite. No se impide la llegada de lo que no se sabe que llega, de lo que no ha llegado ya.

Quizá, tercera doblez: lo que llega sin anuncio y sin visibilidad, sin aviso ni previsibilidad posible, es el quizá mismo, el porvenir como llegada imposible del quizá. Este acontecimiento absoluto, este arribante sin ser, llega en El Rey Lear de Shakespeare para deconstruir finalmente la unidad, para dividir sin premeditación ni conciencia lo que inevitablemente se esperaba unitario.

Al final de la obra, el rey Lear recupera por un instante el poder soberano:

Albany- [...] resignaremos en manos de nuestro anciano monarca la autoridad absoluta para que la goce el resto de sus días. (A Edgardo y a Kent.) Vosotros seréis reintegrados en todos vuestros derechos y se os conferirán nuevos honores que habéis merecido. ${ }^{21}$

El rey consigue recuperar a través de la palabra de Albany el poder que perdió a través de su palabra. Pero, justo en ese instante, la soberanía absoluta vuelve a no ser suficiente y el rey Lear muere ante el cuerpo muerto de su hija Cordelia:

El Rey Lear- ¡Y a mi pobre hija la han estrangulado!... ¡No, no tiene vida! ¿Por qué un perro, un caballo, un ratón, viven, y tú en cambio no respiras?... ¿Ya no te veré más, no! ¡Jamás, jamás, jamás!...Desabrochadme este botón, os lo ruego... ¡Gracias!... ¿Veis, veis? ¡Miradla, miradla!... Sus labios... ¡OH! ¡Mirad, mirad!...

(Pega sus labios a los de Cordelia y muere.) ${ }^{22}$

La tercera muerte del Rey Lear, la muerte de su persona personalis, se produce un instante después de que la soberanía se reagrupase de nuevo en un solo cuerpo, produciendo a su vez y en el mismo gesto de la reunión la división interna idealis/personalis.

El rey fracasa en su intento de división de la soberanía, sus tres hijas mueren, él recupera el poder y muere acto seguido. Pero este final intensamente dramático guarda todavía una vuelta imprevisible. Quizá el único final inesperado y sorprendente. Shakespeare parece estar todavía pensando en la indivisibilidad de la soberanía de Bodin cuando escribe las últimas frases de la pieza de teatro. Con el rey muerto y el reino, por lo tanto, sin cabeza, huérfano, Albany toma por segunda vez en la obra la palabra soberana y dicta la ley que instaurará la futura autoridad:

21 Shakespeare 2003, op. cit. (nota 2), p. 266.

22 Ibídem. 
Albany- Llevad esos cadáveres...Un luto general: he aquí ahora nuestra tarea... (A Kent y a Edgardo.) Amigos míos, los más queridos, gobernad ambos este reino y sed sus sostenes. 23

"Gobernad ambos este reino", dice el Duque de Albany, siendo él la autoridad en este particular "estado de excepción". El Duque, al instituir un nuevo poder gubernativo y evitar así la orfandad del reino, divide una vez más la soberanía. Esta nueva división de la soberanía, lejana a la voluntad del Rey Lear, llega como lo imprevisible mismo, como la venida de lo inaudito. El carácter imposible de la división soberana se pone en entredicho por segunda vez. La obra empieza y acaba con dicha división.

Quizá la imposibilidad que aqueja y limita la división de la soberanía sea simplemente el fruto todavía verde que proviene del árbol ontológico de occidente y hunde sus raíces en una tele-teo-onto-logía político-metafísica. Rastrear sus frutos, dar credibilidad a ciertas semillas allí donde pudieran haber florecido, quizá aporte la convicción de que la división de la soberanía no es simplemente imposible sino que arriba o llega como lo imposible, como la metáfora literaria de una narratividad que florece en el agreste terreno de una posibilidad imposible...

Detengo aquí esta lectura de El Rey Lear de Shakespeare. Y aquí que estamos, de una manera u otra, heredando a Derrida, siéndole infiel por fidelidad, haciendo un trabajo de duelo, yo, como el rey Lear que hizo múltiples duelos: por su hija Cordelia, por su soberanía perdida e incluso por sí mismo; yo quisiera no desaprovechar la oportunidad de este teatro, de estos minutos que amablemente me han sido concedidos, para manifestar también otro duelo y otra herencia, para traer a otro fantasma que a muchos de los aquí presentes nunca nos ha dejado de asediar, de perseguir. Este texto, el que ahora leo casi sin improvisación, lo he escrito en lo que era y seguirá siendo la mesa, la silla, el ordenador de Paco Vidarte. Como ustedes saben, su tesis doctoral, publicada en francés bajo el título "Derritages. Une thèse en déconstruction" es todavía hoy uno de los mejores escritos dedicados a la herencia de y en Derrida. Me gustaría cederle a él, a ese amigo que hacía sacar "el loco que hay en nosotros", los últimos minutos de mi intervención:

"Des-cendre(s) de Derrida decíamos hace no mucho en un deseo contradictorio de pyrificación. Inevitable double bind de la herencia que se le impone a todo comentador. Voluntad de purificar, de extractar lo más importante, lo casi indispensable: antología, monumento. Impotencia ante la pirificación que ello conlleva, la incineración de los restos del padre que hace imposible la memoria, el recuerdo, la arqueología: cenizas, ruina. Frases que no son más que ceniza, condenadas a la dispersión, a la diseminación sin retorno al padre, a ningún origen previo, a ningún sentido preexistente del que fueran resto. Restos de restos amenazados de la disipa-

23 Shakespeare 2003, op. cit. (nota 2), p. 267. 
ción más absoluta, que se retiran ante todo intento de apropiación, de contrasignatura, obligando a nuestra escritura a prolongarse en un duelo sin sentido, melancólico, porque no sabe lo que ha perdido, que quizá sea pura pérdida sin objeto, de un objeto fantasmático llorado con algo de retraso. Pyrificación que no puede sino ser responsable ante la indecidibilidad de preferir éstas a otras cenizas, forzándonos a decidir allí donde la decisión se hace imposible y no puede más que ser sobrevenida. Verdadera experiencia la de rebuscar afanosamente entre unos restos de no se sabe qué Fénix, mientras proseguimos en nuestra lectura incinerante el inevitable holocausto de la herencia. Ya es demasiado tarde para no pensar a partir de Derrida"24. Y también de Paco.

24 Vidarte, P.: Derritages. Une Thèse en déconstruction, L'Harmattan, Paris, 2001, pp. 120-121. 